\title{
BMJ Open Prevalence of positive coeliac disease serology and HLA risk genotypes in a multiethnic population of adults in Canada: a cross-sectional study
}

Joseph Jamnik, ${ }^{1}$ Christopher R Villa, ${ }^{1}$ Sirbarinder Bryn Dhir, ${ }^{1}$ David J A Jenkins, ${ }^{1,2}$ Ahmed El-Sohemy ${ }^{1}$

To cite: Jamnik J, Villa CR, Dhir SB, et al. Prevalence of positive coeliac disease serology and HLA risk genotypes in a multiethnic population of adults in Canada: a crosssectional study. BMJ Open 2017;7:e017678. doi:10.1136/ bmjopen-2017-017678

- Prepublication history and additional material for this paper are available online. To view these files, please visit the journal online (http://dx.doi. org/10.1136/bmjopen-2017017678).

Received 9 May 2017 Accepted 9 August 2017

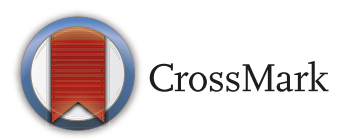

${ }^{1}$ Department of Nutritional Sciences, Faculty of Medicine, University of Toronto, Toronto, Ontario, Canada

${ }^{2}$ Clinical Nutrition and Risk Factor Modification Centre, St Michael's Hospital, Toronto, Ontario, Canada

Correspondence to Professor Ahmed El-Sohemy; a.el.sohemy@utoronto.ca

\section{ABSTRACT}

Objectives Coeliac disease (CD) is a complex autoimmune disorder with known genetic risk factors. Approximately $1 \%$ of individuals of European ancestry have $\mathrm{CD}$, but the prevalence among different ethnicities living in Canada remains unknown. The objective of the present study was to determine the prevalence of positive CD serology in a population of Canadian adults living in Toronto, and to determine whether the prevalence of CD seropositivity and predisposing human leucocyte antigen (HLA)-DQ2/DQ8 risk genotypes differ between major ethnocultural groups.

Design Cross-sectional screening study of participants from the Toronto Nutrigenomics and Health and the Toronto Healthy Diet studies.

Setting University campus and households across Toronto, Canada.

Participants: free-living Adults $(n=2832)$ of diverse ethnocultural backgrounds.

Main outcome measures Prevalence of positive CD serology was determined by screening for antitissue transglutaminase antibodies in individuals with predisposing HLA-DQ2/DQ8 genotypes. HLA genotypes were determined using six single nucleotide polymorphisms in the HLA gene region.

Results Of the 2832 individuals screened, a total of 25 $(0.88 \%$; $95 \% \mathrm{Cl} 0.57 \%$ to $1.30 \%)$ were determined to have positive CD serology. The majority of seropositive CD cases were undiagnosed (87\%). Prevalence was highest among Caucasians (1.48\%; $95 \% \mathrm{Cl} 0.93 \%$ to $2.23 \%$ ), and similar in those of 'Other' $(0.74 \%$; $95 \% \mathrm{Cl} 0.09 \%$ to $2.63 \%)$ or 'Unknown' (0.43; $95 \% \mathrm{Cl} 0.01 \%$ to $2.36 \%$ ) ethnicity. No cases of positive CD serology were identified among East Asian or South Asian individuals. East Asians had a lower prevalence of HLA risk genotypes than Caucasians and South Asians $(p<0.005)$.

Conclusions The prevalence of positive CD serology among Canadian adults living in Toronto is likely $\sim 1 \%$, with $87 \%$ of cases being undiagnosed. These findings suggest the need for better screening in high genetic risk groups. Trial registration number NCT00516620; Post-results.

\section{INTRODUCTION}

Coeliac disease (CD) is an autoimmune disorder with defined genetic risk factors.
Strengths and limitations of this study

- This is the first study to screen for coeliac disease (CD)-associated antibodies in a population of adults living in Canada.

- There was representation of three major ethnic groups living in Canada and a wide age range across study populations included.

- There were low numbers of individuals in some ethnocultural groups examined, and estimates of the prevalence of positive CD serology in these groups should be interpreted with caution.

- Individuals with positive CD serology did not undergo a confirmatory biopsy for a definitive CD diagnosis.

Human leucocyte antigen (HLA)-DQ2 or HLA-DQ8 alleles are considered necessary for the development of $\mathrm{CD}$ as virtually all affected individuals possess these genetic variants. ${ }^{1-3}$ Dietary exposure to gluten, a protein found in wheat, barley and rye, triggers adverse autoimmune reactions in affected individuals. Damage to the intestinal mucosa, which is characteristic of CD, can ultimately result in nutrient malabsorption, and the only effective treatment to date is strict adherence to a gluten-free diet. ${ }^{4}$ Diagnosis of CD is made using a combination of serological tests and a confirmatory biopsy, which remains the gold standard. Individuals typically undergo screening for IgA antitissue transglutaminase (anti-tTG) or antiendomysial antibodies. ${ }^{6}$ Antibodies in the $\operatorname{IgG}$ class are assessed in cases of $\operatorname{IgA}$ deficiency, ${ }^{67}$ which can occur in up to $5 \%$ of individuals with $\mathrm{CD} .{ }^{8}$ Symptoms of $\mathrm{CD}$ may include diarrhoea, steatorrhoea, malnutrition and iron-deficiency anaemia, although adults typically only display some symptoms of gastrointestinal discomfort and many may be relatively asymptomatic. ${ }^{49}$ If untreated, individuals with $\mathrm{CD}$ may be at an increased 
risk for various nutrient deficiencies, ${ }^{10}$ osteoporosis, ${ }^{11}$ infertility, ${ }^{12}$ certain gastrointestinal lymphomas ${ }^{13}$ and overall mortality. ${ }^{14}$

Approximately $1 \%$ of individuals in the USA and many European populations are affected by $\mathrm{CD} .{ }^{14-19}$ Of particular concern is that the prevalence of $\mathrm{CD}$ has been shown to be on the rise. ${ }^{14182021}$ The prevalence of CD in East Asian populations is thought to be much lower than in Caucasians ${ }^{1822}$; however, emerging evidence suggests that $\mathrm{CD}$ may be increasingly prevalent in China,${ }^{23}$ particularly in regions with higher wheat consumption. ${ }^{24} \mathrm{CD}$ has been shown to be more common in individuals of South Asian descent. ${ }^{55-27}$ Variation in the prevalence of HLA-DQ2/DQ8 risk alleles is thought to explain some of the regional variation in $\mathrm{CD}$ prevalence ${ }^{526}$; however, the extent to which such variation influences the prevalence of $\mathrm{CD}$ in immigrant populations is unclear. Furthermore, the prevalence of $\mathrm{CD}$ among Canadian adults, including those of various ethnocultural backgrounds, remains unknown. The objective of this study was to determine the prevalence of positive CD serology in a population of Canadian adults living in Toronto, and to determine whether the prevalence of $\mathrm{CD}$ seropositivity and predisposing HLA-DQ2/DQ8 risk genotypes differ between major ethnocultural groups.

\section{METHODS}

\section{Study populations}

Toronto Nutrigenomics and Health study

The Toronto Nutrigenomics and Health (TNH) study is a cross-sectional cohort of young adults aged 20-29 years living in Toronto, Canada. Subjects $(n=1639)$ were recruited from the University of Toronto campus through postings and advertisements between October 2004 and December 2010. Pregnant or breastfeeding women were excluded from the study. All individuals completed a general health and lifestyle questionnaire, had anthropometric measurements taken, and provided a fasting blood sample for various biomarker assessments and for DNA isolation. The ethnocultural background of each subject was ascertained by self-report. Individuals were classified as either Caucasian (European, Middle Eastern or Hispanic), East Asian (Chinese, Japanese, Korean, Filipino, Vietnamese, Thai or Cambodian), South Asian (Bangladeshi, Indian, Pakistani or Sri Lankan) or Other (Aboriginal Canadians, Afro-Caribbean or individuals belonging to two or more distinct ethnocultural groups). ${ }^{28} \mathrm{~A}$ total of 1620 subjects (1103 women and 517 men) with available plasma samples were included in the study, which was approved by the Research Ethics Board at the University of Toronto.

\section{Toronto Healthy Diet study}

The Toronto Healthy Diet (THD) study is a randomised controlled trial designed to investigate whether increased consumption of fruits, vegetables and whole grains would lead to a reduction in body weight and improvement in biomarkers of obesity-related chronic disease. ${ }^{29}$ The study protocol was registered with ClinicalTrials.gov (NCT00516620) and was approved by the Research Ethics Boards at the University of Toronto and St Michael's Hospital. Households in the Toronto region with at least one person having a body mass index $\geq 25 \mathrm{~kg} / \mathrm{m}^{2}$ were recruited into the study through postings and advertisements. Individuals with chronic conditions, including diagnosed $\mathrm{CD}$, were excluded from the study. A total of 1245 adults $18-82$ years of age provided baseline data, which included anthropometric measurements and a fasting blood sample for biomarker assessment and DNA isolation. The ethnocultural background of participants was assessed by self-report, and individuals were classified into the same groups described above for the TNH study. An additional 'Unknown' ethnocultural group was included for the THD study, where data on ethnicity were missing ( $\mathrm{n}=234)$. All 1212 individuals (901 women and 311 men) with baseline plasma samples available were included in the study.

\section{Genotyping}

HLA genotyping was performed using TaqMan allelic discrimination assays (Applied Biosystems) at the Analytical Genetics Technology Centre at the Princess Margaret Hospital, University Health Network, Toronto, Canada. Genotyping was conducted for six single nucleotide polymorphisms (SNPs) in the HLA region (rs7454108, rs2395182, rs7775228, rs4713586, rs2187668 and rs4639334), which collectively determines the presence of HLA-DQ2/DQ8 alleles associated with $\mathrm{CD}^{30}{ }^{30}$ Subjects were categorised into risk groups for CD based on a previously established HLA gradient. ${ }^{3} \quad$ Subjects with DQA $1 * 0501-\mathrm{DQB} 1 * 0201$ (DQ2.5), DQA1*0301-DQB1*0302 (DQ8) or DQA $1 * 0505-\mathrm{DQB} 1 * 0301 / \mathrm{DQA} 1 * 0201-\mathrm{DQB} 1 * 0202$ (DQ2.2/DQ7) were considered to be at 'elevated risk' for CD compared with the general population. ${ }^{13}$ A total of 2832 subjects underwent genotyping and were included in all analyses.

\section{CD serology}

Anti-tTG antibodies from plasma samples stored at $-80^{\circ} \mathrm{C}$ were measured using human-recombinant tTG ELISA. Only subjects classified as 'elevated risk' for CD based on their HLA-DQ genotype plus all those with at least one copy of DQA1*0201-DQB1*0202 (DQ2.2) had their plasma analysed $(\mathrm{n}=1555)$, since virtually all individuals with $\mathrm{CD}$ possess such alleles. ${ }^{3}$ Initially, samples were analysed using dual-isotope transglutaminase kits screening for tTG antibodies in both the IgA class and IgG class (product no ORG540S; Orgentec Diagnostika, Main, Germany). This was done to account for individuals with selective IgA deficiency, ${ }^{31}$ the primary cause of false-negative test results with tTG IgA screening. ${ }^{32}$ The threshold for a positive test result was $\geq 15 \mathrm{U} / \mathrm{mL}$. All samples that tested positive were then analysed using a separate kit for tTG IgA (product no ORG540A, Orgentec Diagnostika). 
The threshold for a positive test result for tTG IgA was $\geq 10 \mathrm{U} / \mathrm{mL}$. Individuals who tested positive for tTG IgA antibodies were considered to have positive CD serology. Individuals who tested negative for tTG IgA were screened for IgA deficiency using ELISA (product no CSB-E07985h, Cusabio Biotech, Wuhan, China). Individuals with IgA deficiency (total IgA $<7 \mathrm{mg} / \mathrm{dL}$ ) ${ }^{33}$ were then screened using a separate kit for tTG IgG (product no ORG540G; Orgentec Diagnostika). Those with IgA deficiency and positive tTG IgG $(\geq 10 \mathrm{U} / \mathrm{mL})$ were considered to have positive $\mathrm{CD}$ serology. Equivocal results were assigned if the dual-isotope screen was positive, but individuals subsequently tested negative for tTG IgA antibodies and were IgA-sufficient. Such cases are likely driven by tTG IgG, and screening for such antibodies is not recommended due to the low diagnostic utility of tTG IgG in IgA-sufficient populations. ${ }^{32} 34$ Individuals in the TNH population who reported having been diagnosed with $\mathrm{CD}$ on the general health and lifestyle questionnaire were also considered to have positive $\mathrm{CD}$ serology.

\section{Statistical analysis}

Statistical analyses were conducted using Statistical Analysis Software V.9.2. For all analyses, the $\alpha$-error was set at 0.05 and reported $\mathrm{p}$ values are two-sided. Continuous variables were $\log _{\mathrm{e}}$-transformed or square root-transformed to improve normality where necessary. Although reported $\mathrm{p}$ values are from models using transformed variables, means and measures of spread for such variables are reported in their untransformed state to facilitate interpretability. Binomial 95\% CIs (Clopper-Pearson) were calculated for all dichotomous variables.

Subject characteristics between the two study populations were assessed using analysis of covariance and $\chi^{2}$ tests for continuous and categorical variables, respectively. Fisher's exact test was used to determine whether there were differences in the frequency of the HLA-DQ2/DQ8 elevated-risk genotypes between ethnocultural groups. All possible pairs of ethnocultural groups were compared. The Bonferroni adjustment for multiple testing was used to account for the multiple pairwise comparisons $(\mathrm{p}<0.005$, calculated based on 10 pairwise comparisons and $\alpha=0.05$ ). Differences in the prevalence of positive CD serology between the two study populations were assessed using exact logistic regression adjusted for sex and ethnicity. Exact logistic regression adjusted for ethnicity and study population was also used to assess differences in the proportion of men and women with elevated tTG antibodies.

\section{RESULTS}

Subject characteristics for both study populations are shown in table 1 . Differences $(\mathrm{p}<0.05)$ in age, sex, ethnocultural status, anthropometric measurements, blood pressure, blood glucose and lipid profiles were observed between study populations.
Table 1 Subject characteristics for TNH and THD study populations

\begin{tabular}{|c|c|c|c|}
\hline & TNH study & THD study & $\mathbf{p}$ \\
\hline Subjects (n) & 1620 & 1212 & \\
\hline Age (year) & $22.7 \pm 0.06^{*}$ & $44.7 \pm 0.36$ & $<0.0001$ \\
\hline $\operatorname{Sex}(n(\%))$ & & & 0.0003 \\
\hline Female & $1103(68)$ & $901(74)$ & \\
\hline Male & $517(32)$ & $311(26)$ & \\
\hline Ethnicity (n (\%)) & & & $<0.0001$ \\
\hline Caucasian & $769(47)$ & $721(59)$ & \\
\hline East Asian & $560(35)$ & $54(4)$ & \\
\hline South Asian & $173(11)$ & $49(4)$ & \\
\hline Other & $118(7)$ & $154(13)$ & \\
\hline Unknown & - & $234(19)$ & \\
\hline $\mathrm{BMI}\left(\mathrm{kg} / \mathrm{m}^{2}\right)$ & $22.9 \pm 0.09$ & $32.5 \pm 0.17$ & $<0.0001$ \\
\hline $\begin{array}{l}\text { Waist circumference } \\
(\mathrm{cm})\end{array}$ & $74.4 \pm 0.23$ & $102.1 \pm 0.42$ & $<0.0001$ \\
\hline $\begin{array}{l}\text { Systolic blood } \\
\text { pressure (mm Hg) }\end{array}$ & $114 \pm 0.29$ & $115 \pm 0.36$ & $<0.0001$ \\
\hline $\begin{array}{l}\text { Diastolic blood } \\
\text { pressure (mm Hg) }\end{array}$ & $69 \pm 0.20$ & $73 \pm 0.26$ & $<0.0001$ \\
\hline Glucose (mmol/L) & $4.79 \pm 0.01$ & $4.91 \pm 0.02$ & $<0.0001$ \\
\hline \multicolumn{4}{|l|}{ Cholesterol } \\
\hline Total(mmol/L) & $4.26 \pm 0.02$ & $5.07 \pm 0.03$ & 0.02 \\
\hline $\mathrm{HDL}(\mathrm{mmol} / \mathrm{L})$ & $1.54 \pm 0.01$ & $1.27 \pm 0.01$ & $<0.0001$ \\
\hline LDL (mmol/L) & $2.28 \pm 0.02$ & $3.23 \pm 0.02$ & $<0.0001$ \\
\hline $\begin{array}{l}\text { Total:HDL } \\
\text { cholesterol }\end{array}$ & $2.91 \pm 0.02$ & $4.23 \pm 0.04$ & $<0.0001$ \\
\hline
\end{tabular}

*Mean \pm SE (all such values). Differences between study populations were assessed using $\chi^{2}$ tests for categorical variables and ANCOVA-adjusted for age, sex, BMI and ethnicity for continuous variables.

ANCOVA, analysis of covariance; BMI, body mass index; HDL, high density lipoprotein; LDL, low density lipoprotein; THD, Toronto Healthy Diet; TNH, Toronto Nutrigenomics and Health.

\section{HLA-DQ genotypes}

The overall prevalence of elevated-risk HLA-DQ2/DQ8 genotypes across both study populations was $38.4 \%$ (95\% CI $36.6 \%$ to $40.2 \%$ ). The proportion of individuals with elevated-risk HLA-DQ genotypes in each ethnocultural group is shown in figure 1. Caucasians and South Asians had a higher proportion of elevated-risk HLA genotypes than East Asians $(p<0.005)$, while individuals in the 'Other' and 'Unknown' groups had an intermediate prevalence of such alleles. A breakdown of all HLA-DQ subcategories by ethnocultural group is shown in online supplementary figure S1. Generally, the presence of higher risk HLA-DQ risk alleles was increasingly rare as their associated CD risk increased across all ethnocultural groups.

\section{Anti-tTG antibodies}

A total of 46 individuals tested positive on the initial dual-isotope tTG-IgA/IgG screen. Of these individuals, 


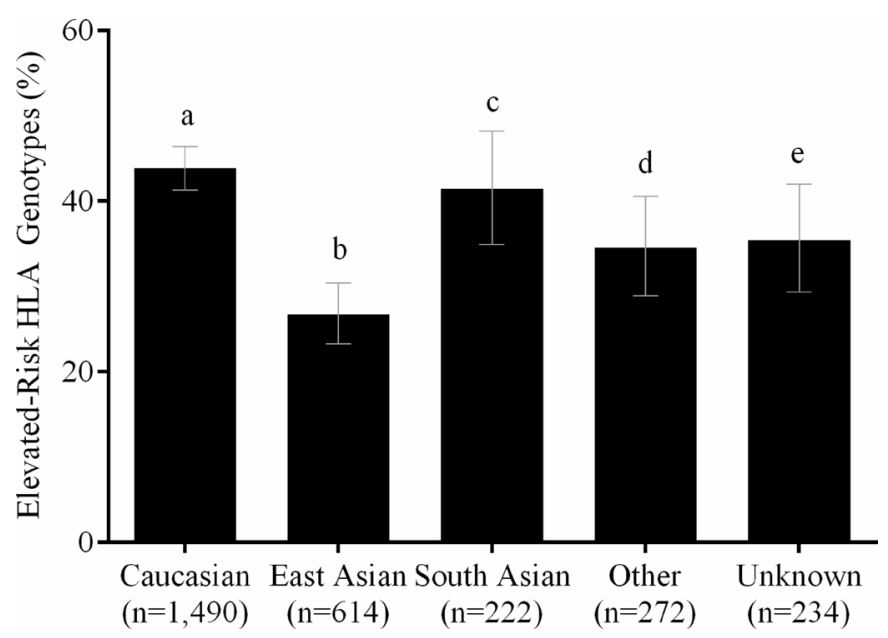

Figure 1 Prevalence of coeliac disease-associated elevated-risk HLA genotypes across ethnocultural groups. Elevated-risk genotypes include DQA $1{ }^{*} 0501-\mathrm{DQB} 1{ }^{*} 0201$ (DQ2.5), DQA1*0301-DQB1*0302 (DQ8) or DQA1*0505DQB1*0301/DQA1*0201-DQB1*0202 (DQ2.2/DQ7).

Differences in the prevalence of elevated-risk genotypes between groups were compared using Fisher's exact test. All pairs of ethnocultural groups were compared, and a Bonferroni correction was applied to account for the multiple pairwise tests $(p<0.005$, calculated based on 10 pairwise comparisons and $\alpha=0.05)$. a versus $b$, a versus $d, b$ versus c: $p<0.005 ; p>0.005$ for all other comparisons. Error bars represent $95 \% \mathrm{CI}$. HLA, human leucocyte antigen.

22 tested positive for tTG IgA antibodies and were considered to have positive CD serology. Of the individuals who tested positive on the dual-isotope screen but negative for tTG IgA, one individual was found to be IgA-deficient (total $\operatorname{IgA}<7 \mathrm{mg} / \mathrm{dL}$ ) and tested positive for tTG IgG antibodies. This individual was also considered to have positive CD serology. Two additional individuals who reported having been diagnosed with $\mathrm{CD}$ were also considered to have positive $\mathrm{CD}$ serology. Both of these individuals possessed HLA-DQ2 and/or HLA-DQ8 genotypes but were tTG-negative, likely due to their adherence to a strict gluten-free diet. In total, 25 individuals were identified with positive $\mathrm{CD}$ serology, which translates to an overall prevalence of $1: 114(0.88 \% ; 95 \%$ CI $0.57 \%$ to $1.30 \%)$. In the TNH study population, 13 out of $15(87 \%)$ cases were identified exclusively through serology and did not report having been diagnosed with $\mathrm{CD}$ in the health questionnaire. These likely represent cases of undiagnosed CD. Estimates on the ratio of undiagnosed to diagnosed cases of CD were not available for the THD study population since a diagnosis of $\mathrm{CD}$ would have excluded individuals from the study. Estimates for the prevalence of CD across ethnocultural groups are shown in table 2. The majority of individuals with positive CD serology were Caucasian. No cases of positive serology were identified among East Asian or South Asian individuals, while a limited number of cases were identified among those of 'Other' and 'Unknown' ancestry. The prevalence did not differ between the TNH population $(0.93 \%$; $95 \%$ CI $0.52 \%$ to $1.52 \%)$ and the THD population $(0.83 \%$;
Table 2 Prevalence of positive coeliac disease (CD) serology across ethnocultural groups*

\begin{tabular}{lll}
\hline Ethnocultural group & Cases $(\mathbf{n})$ & $\begin{array}{l}\text { Prevalence }(\% \\
(\mathbf{9 5 \%} \mathbf{C l}))\end{array}$ \\
\hline Total population $(\mathrm{n}=2832)$ & 25 & $0.88(0.57$ to 1.30$)$ \\
Caucasian $(n=1490)$ & 22 & $1.48(0.93$ to 2.23$)$ \\
East Asian $(n=614)$ & 0 & - \\
South Asian $(n=222)$ & 0 & - \\
Other $(n=272)$ & 2 & $0.74(0.09$ to 2.63$)$ \\
Unknown $(n=234)$ & 1 & $0.43(0.01$ to 2.36$)$ \\
\hline
\end{tabular}

${ }^{*}$ Cases of CD were determined by measuring levels of antitissue transglutaminase (anti-tTG) IgA antibodies and previous diagnosis. tTG IgG antibodies were assessed in cases of IgA deficiency.

$95 \%$ CI $0.40 \%$ to $1.51 \%$ ) after adjusting for sex and ethnicity $(\mathrm{p}=0.32)$. There was no difference in the prevalence between men $(0.72 \% ; 95 \%$ CI $0.27 \%$ to $1.57 \%)$ and women $(0.95 \%$; $95 \%$ CI $0.57 \%$ to $1.48 \%$ ) after adjusting for study population and ethnicity $(\mathrm{p}=0.74)$. The proportion of individuals with positive $\mathrm{CD}$ serology by subcategory of HLA risk is shown in figure 2. The proportion of individuals with positive serology tended to increase with increasing predefined HLA risk status, ${ }^{3}$ although differences between risk groups were not statistically significant $(\mathrm{p}>0.05)$.

\section{DISCUSSION}

CD represents a common autoimmune condition in North America and Europe. ${ }^{35}$ The prevalence of CD is known to vary globally and is thought to be particularly rare in certain regions, notably in Asia. ${ }^{518} 26$ Differences

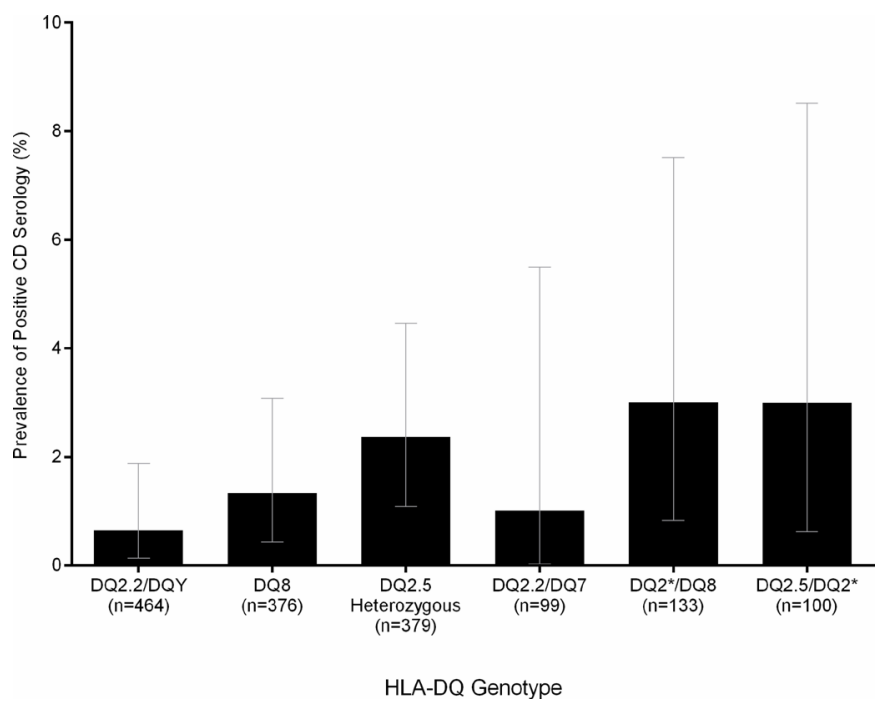

Figure 2 Prevalence of elevated tissue transglutaminase antibodies by CD-associated HLA-DQ risk category. HLA risk groups (increasing risk from left to right) modified from previously established risk gradient. ${ }^{3}$ Error bars represent 95\% Cls. DQY, DQ2.2 or non-DQ2/DQ8 type; DQ8, DQ8 heterozygotes and homozygotes; DQ2*, DQ2.2 or DQ2.5 type. CD, coeliac disease; HLA, human leucocyte antigen. 
in the prevalence of HLA variants conferring susceptibility to $\mathrm{CD}$ partially explain variability in the prevalence of $\mathrm{CD}$ observed between nations ${ }^{18}{ }^{26}$; however, it is unclear whether such variation plays a role in the development of $\mathrm{CD}$ in individuals of different ethnicities living in North America. Furthermore, there is a notable lack of screening studies assessing the prevalence of $\mathrm{CD}$ in individuals from diverse ethnocultural backgrounds living in Canada. To our knowledge, the present study is the first to screen for CD-associated antibodies in a population of Canadian adults. We found the prevalence of positive CD serology among ethnoculturally diverse Canadians living in Toronto to be $0.88 \%$ (95\% CI $0.57 \%$ to $1.30 \%$ ), which is similar to estimates in Europe and the USA. ${ }^{14-19}$ Furthermore, $87 \%$ of possible CD cases were undiagnosed, which is consistent with commonly reported figures of about $85 \%,{ }^{9536}$ and consistent with findings from the Canadian Celiac Association Health Survey indicating an average delay in diagnosis of $\sim 12$ years after the onset of symptoms. ${ }^{37}$ Caucasians comprised the majority of cases with positive CD serology, while no individuals of East Asian or South Asian descent had positive serology or a previous diagnosis. Compared with Caucasians, East Asians had a lower prevalence of HLA-DQ elevated-risk genotypes, while South Asians and Caucasians had a similar prevalence of such genotypes.

Strengths of the present study include its large sample size and representation of three major ethnic groups living in Canada. Furthermore, individuals were not selected based on suspicion of $\mathrm{CD}$, and estimates of the prevalence of undiagnosed CD are likely not inflated compared with the general population. There are, however, some notable limitations. There were low numbers of individuals in some ethnocultural groups examined, and estimates of the prevalence of positive CD serology in these groups should be interpreted with caution. Furthermore, while the populations included were from Toronto, Canada's largest metropolis, the results may not be generalisable to all Canadian adults. There was an over-representation of women in the study population due to the self-selected nature of the study participants. Additionally, although human-recombinant tTG IgA assays have a sensitivity and specificity of $98 \%$ for CD on average, ${ }^{32}$ subjects with positive serology did not undergo a confirmatory biopsy for a definitive diagnosis of CD. This also precluded the assessment of CD severity in cases of positive serology. The HLA genotyping methodology employed in the present study was optimised for European populations, and it is possible that other, currently unidentified tag SNPs in the HLA region serve as alternate markers for the predisposing HLA-DQ genotypes required for the development of $\mathrm{CD}$ in non-European populations. ${ }^{30}$ Finally, while $13 \%$ of likely CD cases in the TNH population were previously diagnosed, we were unable to assess cases of diagnosed $\mathrm{CD}$ in the THD cohort since such individuals would have been excluded from the study. However, if a similar ratio of diagnosed to undiagnosed cases between study populations is assumed, this would equate to an additional two individuals with clinically diagnosed CD in the THD cohort, increasing the prevalence of positive CD serology to 27 out of $2834(0.95 \%$; $95 \%$ CI $0.63 \%$ to $1.38 \%)$ in our multiethnic population of Canadian adults.

CD is known to vary by ethnicity and has historically been considered to primarily affect Caucasians. ${ }^{538}$ Our findings indicate that Caucasians are among the highest risk ethnocultural groups for CD in Canada. In contrast, $\mathrm{CD}$ is rare in East Asia, ${ }^{1822}$ although case reports have been previously documented in East Asians living in Canada. ${ }^{39}$ This is consistent with our findings that $\mathrm{CD}$ is rare in East Asians, and this is partly due to the lower prevalence of HLA-DQ2/DQ8 risk alleles. Conversely, we found that the prevalence of risk alleles in South Asians is similar to the prevalence of such alleles in Caucasians. This suggests that CD may occur in South Asians at a frequency that approaches that of Caucasians. Indeed, although we did not identify any South Asians with positive CD serology in the present study, screening studies in South Asian populations around the world suggest that $\mathrm{CD}$ may affect individuals at frequencies similar to Caucasians. ${ }^{25} 40-42$

Demographic characteristics of individuals with CD are of considerable interest. We observed no difference in the prevalence of positive CD serology between men and women. While it has been reported that more women are diagnosed with $\mathrm{CD},{ }^{4}$ our results are in agreement with other screening studies that report similar rates of $\mathrm{CD}$ between sexes. ${ }^{15}{ }^{36}$ Screening studies have also suggested that the prevalence of $\mathrm{CD}$ is similar across age groups. ${ }^{14151936}$ In agreement with these findings, we observed no significant difference in the prevalence of positive CD serology between the TNH and THD cohorts, populations with average ages of 23 and 45 years, respectively. Finally, while rare in the general population, IgA deficiency occurs more often in $\mathrm{CD},{ }^{32}$ affecting roughly $3 \%-5 \%$ of individuals with this condition. ${ }^{8}$ Consistent with these estimates, we found that 1 out of $23(4.3 \%)$ individuals with positive CD serology was IgA-deficient.

We observed a pattern of elevated tTG antibodies by HLA risk subcategories consistent with previously established HLA-DQ risk gradients. ${ }^{3}$ However, the reference HLA risk groupings were generated in an at-risk population from the USA, ${ }^{3}$ and it has been shown that the prevalence of certain HLA alleles in individuals of different ethnocultural backgrounds with CD differs from the prevalence of such alleles in Caucasians with $\mathrm{CD} .{ }^{42}$ Moreover, emerging evidence suggests that additional HLA variants may act as potential CD risk factors in certain ethnocultural groups, for example the HLA-DQ9.3 haplotype in individuals of Chinese descent. ${ }^{43}$ This suggests that HLA risk stratification for $\mathrm{CD}$ may be population-dependent. Additionally, it is possible that other genetic regions that confer susceptibility to CD may be of increased importance in certain ethnocultural groups. Indeed, genomewide studies have identified several other genetic variants that account for additional fractions of the genetic risk for $\mathrm{CD} .{ }^{1}$ It is possible that such variants, coupled with HLA-DQ genotypes, may be particularly useful in 
establishing genetic risk gradients for $\mathrm{CD}$ in individuals of non-Caucasian ancestry. ${ }^{42}$ Nevertheless, a large screening study for $\mathrm{CD}$ in China found that all individuals with $\mathrm{CD}$ autoimmunity had the HLA-DQ2 genotype,${ }^{24}$ and further research is necessary to better understand the influence of ethnicity-specific genetic risk factors in the development of CD.

Many factors in addition to genetics are thought to contribute to risk of developing CD. Differences in per capita wheat consumption between countries are associated with the population prevalence of CD. Indeed, CD is rare in China and Japan, where per capita wheat consumption is relatively low and traditional diets are based on rice. ${ }^{518} 26$ The timing of first gluten exposure was long thought to play a role in the development of $\mathrm{CD}^{44}$; however, this has recently been called into question and it is unclear whether the initial introduction of gluten into the diet influences risk of developing CD in at-risk infants. ${ }^{456}$ Exposure to certain viral infections during first introduction of gluten is thought to possibly prime the immune system and increase the risk of developing $\mathrm{CD}^{47}{ }^{48}$ Interactions between the gut microbiota and the intestinal mucosa can also affect the immune system. ${ }^{49}$ Gut microbiota profiles have been shown to differ between patients with $\mathrm{CD}$ and healthy controls, and it is thought that bacteria-mediated inflammation in the mucosa may also play a role in the development of $\mathrm{CD}^{50}$ Dietary patterns are known to influence the composition of the gut microbiota. ${ }^{51}$ Furthermore, differences in dietary patterns between ethnicities have been identified. ${ }^{52}$ It is, therefore, possible that differences in broad dietary patterns between ethnocultural groups may explain some of the observed variation in the prevalence of $\mathrm{CD}$ between such groups.

\section{CONCLUSION}

We demonstrated that 1 in 114 Canadian adults $(0.88 \%)$ has positive CD serology. We also report that $87 \%$ of cases are likely undiagnosed. Caucasians had the highest prevalence of positive CD serology as well as HLA-DQ2/8 elevated-risk alleles. While no individuals of East Asian or South Asian descent were found to have positive CD serology, high risk HLA-DQ2/8 alleles were equally prevalent in South Asians and Caucasians, but lower in East Asians. This study highlights the likely high prevalence of undiagnosed CD in Canada, and emphasises the importance of serological screening in patients with high-risk HLA genotypes.

Contributors JJ and AE-S designed the study. AE-S and DJAJ secured funding. JJ, $\mathrm{CRV}$ and SBD performed the analyses. JJ analysed the data and wrote the initial draft. All authors reviewed the manuscript. AE-S had primary responsibility for final content.

Funding This work was supported by the Canadian Institutes of Health Research. $\mathrm{JJ}$ is a recipient of a Canadian Institutes of Health Research Doctoral Research Award.

Competing interests AE-S holds shares in Nutrigenomix, a genetic testing company for personalised nutrition. DJAJ has received research grants from
Saskatchewan Pulse Growers, the Agricultural Bioproducts Innovation Program through the Pulse Research Network, the Advanced Foods and Material Network, Loblaw Companies, Unilever, Barilla, the Almond Board of California, Agriculture and Agri-Food Canada, Pulse Canada, Kellogg's Company, Canada, Quaker Oats, Canada, Procter \& Gamble Technical Centre, Bayer Consumer Care, Springfield, NJ, Pepsi/Quaker, International Nut \& Dried Fruit (INC), Soy Foods Association of North America, the Coca Cola Company (investigator-initiated, unrestricted grant), Solae, Hain Celestial, the Sanitarium Company, Orafti, the International Tree Nut Council Nutrition Research and Education Foundation, the Peanut Institute, the Canola and Flax Councils of Canada, the Calorie Control Council (CCC), the CIHR, the Canada Foundation for Innovation, and the Ontario Research Fund. He has been on the speaker's panel, served on the scientific advisory board and/or received travel support and/or honoraria from the Almond Board of California, Canadian Agriculture Policy Institute, Loblaw Companies, Nutrigenomix, the Griffin Hospital (for the development of the NuVal scoring system), the Coca Cola Company, EPICURE, Danone, Saskatchewan Pulse Growers, Sanitarium Company, Orafti, the Almond Board of California, the American Peanut Council, the International Tree Nut Council Nutrition Research and Education Foundation, the Peanut Institute, Herbalife International, Pacific Health Laboratories, Nutritional Fundamental for Health, Barilla, Metagenics, Bayer Consumer Care, Unilever Canada and Netherlands, Solae, Kellogg, Quaker Oats, Procter \& Gamble, the Coca Cola Company, the Griffin Hospital, Abbott Laboratories, the Canola Council of Canada, Dean Foods, the California Strawberry Commission, Hain Celestial, PepsiCo, the Alpro Foundation, Pioneer Hi-Bred International, DuPont Nutrition and Health, Spherix Consulting and WhiteWave Foods, the Advanced Foods and Material Network, the Canola and Flax Councils of Canada, the Nutritional Fundamentals for Health, Agriculture and Agri-Food Canada, the Canadian Agri-Food Policy Institute, Pulse Canada, the Saskatchewan Pulse Growers, the Soy Foods Association of North America, the Nutrition Foundation of Italy (NFI), Nutrasource Diagnostics, the McDougall Program, the Toronto Knowledge Translation Group (St Michael's 344 Hospital), the Canadian College of Naturopathic Medicine, The Hospital for Sick Children, the Canadian Nutrition Society (CNS), the American Society of Nutrition (ASN), Arizona State University, Paolo Sorbini Foundation, and the Institute of Nutrition, Metabolism and Diabetes. He received an honorarium from the US Department of Agriculture to present the 2013 W 0 Atwater Memorial Lecture. He received the 2013 Award for Excellence in Research from the International Nut and Dried Fruit Council. He received funding and travel support from the Canadian Society of Endocrinology and Metabolism to produce mini cases for the Canadian Diabetes Association (CDA). $\mathrm{He}$ is a member of the International Carbohydrate Quality 352 Consortium (ICQC). His wife, ALJ, is a director and partner of Glycemic Index Laboratories, and his sister received funding through a grant from the St Michael's Hospital Foundation 354 to develop a cookbook for one of his studies. JJ, CRV and SBD have no conflicts of interest to declare.

Ethics approval Research Ethics Boards at the University of Toronto and St Michael's Hospital.

Provenance and peer review Not commissioned; externally peer reviewed.

Data sharing statement Data will be made available to all interested researchers upon request to the corresponding author.

Open Access This is an Open Access article distributed in accordance with the Creative Commons Attribution Non Commercial (CC BY-NC 4.0) license, which permits others to distribute, remix, adapt, build upon this work non-commercially, and license their derivative works on different terms, provided the original work is properly cited and the use is non-commercial. See: http://creativecommons.org/ licenses/by-nc/4.0/

(c) Article author(s) (or their employer(s) unless otherwise stated in the text of the article) 2017. All rights reserved. No commercial use is permitted unless otherwise expressly granted.

\section{REFERENCES}

1. Dieli-Crimi $R$, Cénit MC, Núñez $C$. The genetics of celiac disease: A comprehensive review of clinical implications. J Autoimmun 2015;64:26-41.

2. Karell K, Louka AS, Moodie SJ, et al. HLA types in celiac disease patients not carrying the $\mathrm{DQA} 1^{\star} 05-\mathrm{DQB1}{ }^{*} 02(\mathrm{DQ} 2)$ heterodimer: results from the European Genetics Cluster on Celiac Disease. Hum Immunol 2003;64:469-77.

3. Pietzak MM, Schofield TC, McGinniss MJ, et al. Stratifying risk for celiac disease in a large at-risk United States population by using HLA alleles. Clin Gastroenterol Hepatol 2009;7:966-71. 
4. Green PH, Cellier C. Celiac disease. N Engl J Med 2007;357:1731-43.

5. Gujral N, Freeman HJ, Thomson AB, et al. diagnosis, pathogenesis and treatment. World J Gastroenterol 2012;18:6036-59.

6. Nandiwada SL, Tebo AE. Testing for antireticulin antibodies in patients with celiac disease is obsolete: a review of recommendations for serologic screening and the literature. Clin Vaccine Immunol 2013;20:447-51.

7. Wang N, Truedsson L, Elvin K, et al. Serological assessment for celiac disease in IgA deficient adults. PLoS One 2014;9:e93180.

8. Halfdanarson TR, Litzow MR, Murray JA. Hematologic manifestations of celiac disease. Blood 2007;109:412-21.

9. Kagnoff MF. Celiac disease: pathogenesis of a model immunogenetic disease. J Clin Invest 2007;117:41-9.

10. Caruso R, Pallone F, Stasi E, et al. Appropriate nutrient supplementation in celiac disease. Ann Med 2013;45:522-31.

11. Vasquez $\mathrm{H}$, Mazure R, Gonzalez D, et al. Risk of fractures in celiac disease patients: a cross-sectional, case-control study. Am J Gastroenterol 2000;95:183-9.

12. Tersigni $\mathrm{C}$, Castellani R, de Waure $\mathrm{C}$, et al. Celiac disease and reproductive disorders: meta-analysis of epidemiologic associations and potential pathogenic mechanisms. Hum Reprod Update 2014;20:582-93.

13. Catassi C, Bearzi I, Holmes GK. Association of celiac disease and intestinal lymphomas and other cancers. Gastroenterology 2005;128:S79-S86.

14. Rubio-Tapia A, Kyle RA, Kaplan EL, et al. Increased prevalence and mortality in undiagnosed celiac disease. Gastroenterology 2009;137:88-93.

15. Fasano A, Berti I, Gerarduzzi T, et al. Prevalence of celiac disease in at-risk and not-at-risk groups in the United States: a large multicenter study. Arch Intern Med 2003;163:286-92.

16. Mardini HE, Westgate P, Grigorian AY. Racial Differences in the Prevalence of Celiac Disease in the US Population: National Health and Nutrition Examination Survey (NHANES) 2009-2012. Dig Dis Sci 2015;60:1738-42.

17. Mustalahti $\mathrm{K}$, Catassi $\mathrm{C}$, Reunanen $\mathrm{A}$, et al. The prevalence of celiac disease in Europe: results of a centralized, international mass screening project. Ann Med 2010;42:587-95.

18. Kang JY, Kang AH, Green A, et al. Systematic review: worldwide variation in the frequency of coeliac disease and changes over time. Aliment Pharmacol Ther 2013;38:226-45.

19. Kim HS, Patel KG, Orosz E, et al. Time Trends in the Prevalence of Celiac Disease and Gluten-Free Diet in the US Population: Results From the National Health and Nutrition Examination Surveys 20092014. JAMA Intern Med 2016;176:1716-1717.

20. Lohi S, Mustalahti K, Kaukinen K, et al. Increasing prevalence of coeliac disease over time. Aliment Pharmacol Ther 2007;26:1217-25.

21. Ludvigsson JF, Rubio-Tapia A, van Dyke CT, et al. Increasing incidence of celiac disease in a North American population. Am J Gastroenterol 2013;108:818-24.

22. Fukunaga $\mathrm{M}$, Ishimura $\mathrm{N}$, Fukuyama $\mathrm{C}$, et al. Celiac disease in nonclinical populations of Japan. J Gastroenterol 2017.

23. Zhao Z, Zou J, Zhao L, et al. Celiac Disease Autoimmunity in Patients with Autoimmune Diabetes and Thyroid Disease among Chinese Population. PLoS One 2016;11:e0157510.

24. Yuan J, Zhou C, Gao J, et al. Prevalence of Celiac Disease Autoimmunity Among Adolescents and Young Adults in China. Clin Gastroenterol Hepatol 2017.

25. Ramakrishna BS, Makharia GK, Chetri K, et al. Prevalence of Adult Celiac Disease in India: Regional Variations and Associations. Am J Gastroenterol 2016:111:115-23.

26. Cummins AG, Roberts-Thomson IC. Prevalence of celiac disease in the Asia-Pacific region. J Gastroenterol Hepatol 2009;24:1347-51.

27. Singh P, Arora S, Singh A, et al. Prevalence of celiac disease in Asia: A systematic review and meta-analysis. J Gastroenterol Hepatol 2016;31:1095-101.
28. García-Bailo B, Brenner DR, Nielsen D, et al. Dietary patterns and ethnicity are associated with distinct plasma proteomic groups. Am J Clin Nutr 2012;95:352-61.

29. Jenkins DJA, Boucher BA, Ashbury FD, et al. Effect of Current Dietary Recommendations on Weight Loss and Cardiovascular Risk Factors. J Am Coll Cardiol 2017;69:1103-12.

30. Monsuur AJ, de Bakker PI, Zhernakova A et al. Effective detection of human leukocyte antigen risk alleles in celiac disease using tag single nucleotide polymorphisms. PLoS One 2008;3:e2270.

31. Reeves GE, Squance ML, Duggan AE, et al. Diagnostic accuracy of coeliac serological tests: a prospective study. Eur J Gastroenterol Hepatol 2006;18:493-501.

32. Leffler DA, Schuppan D. Update on serologic testing in celiac disease. Am J Gastroenterol 2010;105:2520-4.

33. Bonilla FA, Khan DA, Ballas ZK, et al. Practice parameter for the diagnosis and management of primary immunodeficiency. J Allergy Clin Immunol 2015;136:1186-205.

34. Absah I, Rishi AR, Gebrail R, et al. Lack of Utility of Anti-tTG IgG to Diagnose Celiac Disease When Anti-tTG IgA Is Negative. J Pediatr Gastroenterol Nutr 2017;64:726-9.

35. Guandalini S, Assiri A. Celiac disease: a review. JAMA Pediatr 2014;168:272-8.

36. Rubio-Tapia A, Ludvigsson JF, Brantner TL, et al. The prevalence of celiac disease in the United States. Am J Gastroenterol 2012;107:1538-44.

37. Cranney A, Zarkadas M, Graham ID, et al. The Canadian Celiac Health Survey. Dig Dis Sci 2007;52:1087-95.

38. Cataldo F, Montalto G. Celiac disease in the developing countries: a new and challenging public health problem. World J Gastroenterol 2007;13:2153-9.

39. Freeman HJ. Biopsy-defined adult celiac disease in AsianCanadians. Can J Gastroenterol 2003;17:433-6.

40. Sher KS, Fraser RC, Wicks AC, et al. High risk of coeliac disease in Punjabis. Epidemiological study in the south Asian and European populations of Leicestershire. Digestion 1993;54:178-82.

41. Sood A, Midha V, Sood N, et al. Prevalence of celiac disease among school children in Punjab, North India. J Gastroenterol Hepatol 2006;21:1622-5.

42. Butterworth JR, Iqbal TH, Cooper BT. Coeliac disease in South Asians resident in Britain: comparison with white Caucasian coeliac patients. Eur J Gastroenterol Hepatol 2005;17:541-5.

43. Wang $\mathrm{H}$, Zhou G, Luo L, et al. Serological Screening for Celiac Disease in Adult Chinese Patients With Diarrhea Predominant Irritable Bowel Syndrome. Medicine 2015;94:e1779.

44. Norris $\mathrm{JM}$, et al. Risk of celiac disease autoimmunity and timing of gluten introduction in the diet of infants at increased risk of disease. Jama 2005;293:2343-51.

45. Lionetti E, Castellaneta S, Francavilla $\mathrm{R}$, et al. Introduction of gluten, HLA status, and the risk of celiac disease in children. N Engl J Med 2014;371:1295-303.

46. Vriezinga SL, Auricchio R, Bravi E, et al. Randomized feeding intervention in infants at high risk for celiac disease. N Engl J Med Overseas Ed 2014;371:1304-15.

47. Myléus A, Hernell O, Gothefors L, et al. Early infections are associated with increased risk for celiac disease: an incident casereferent study. BMC Pediatr 2012;12:194.

48. Stene LC, Honeyman MC, Hoffenberg EJ, et al. Rotavirus infection frequency and risk of celiac disease autoimmunity in early childhood: a longitudinal study. Am J Gastroenterol 2006;101:2333-40.

49. Belkaid $Y$, Hand TW. Role of the microbiota in immunity and inflammation. Cell 2014;157:121-41.

50. Verdu EF, Galipeau HJ, Jabri B. Novel players in coeliac disease pathogenesis: role of the gut microbiota. Nat Rev Gastroenterol Hepatol 2015;12:497-506.

51. Gd W, Chen J, Hoffmann C, et al. Linking long-term dietary patterns with gut microbial enterotypes. Science 2011;334:105-8.

52. Brenner DR, Boucher BA, Kreiger N, et al. Dietary patterns in an ethnoculturally diverse population of young Canadian adults. Can J Diet Pract Res 2011;72:e161-e168. 